\title{
Manuais Pedagógicos em Comparação: Cours Pratique de Pédagogie, de Daligault (1851), e Compêndio de Pedagogia, de B. J. M. Cordeiro (1874)
}

\author{
Pedagogical Manuals in Comparison: Cours Pratique de Pédagogie, de Daligault \\ (1851), and Compêndio de Pedagogia of B. J. M. Cordeiro (1874)
}

\begin{abstract}
Manuales Pedagógicos en Comparación: Cours Pratique de Pédagogie, de Daligault (1851) y Compendio de Pedagogia, de B. J. M. Cordeiro (1874)
\end{abstract}

JosÉ CARLOS SOUZA ARAUJO ${ }^{1}$

\section{Resumo}

O objeto dessa investigação é de caráter comparativo, e envolve dois manuais pedagógicos, destinados à formação docente, que vieram a público no Brasil na segunda metade do século XIX, um de origem francesa, e o outro brasileira. Serão privilegiadas as concepções de Educação, ângulo teórico da Pedagogia, neles presentes. Seus autores são, pela ordem, Jean-Baptiste Daligault e Braulio Jayme Muniz Cordeiro. Tais manuais serão enfocados como expressões singulares da Pedagogia da Essência, através da vertente humanista cristã, mas encontram-se assentados em relações culturais, políticas, religiosas, educacionais e escolares. De um lado, são singulares em relação à totalidade social, constituindo-se como compartilhantes do processo de formação e qualificação docente no Brasil, àquela altura ainda através das escolas de primeiras letras; de outro, em termos de totalidade social, estão radicados em concepções fundadas na Antropologia, na Ética, na Metafísica de caráter teológico, na Política, no Civismo, na Teologia, na Pedagogia, porém demarcadas pela visão de mundo cristã.

Palavras-chave: Pedagogia. Manuais Pedagógicos. Formação de Professores. Escolas Normais. Teorias Pedagógicas.

\footnotetext{
${ }^{1}$ Doutor em Educação pela Universidade Estadual de Campinas. Professor Permanente do Programa de Pós-Graduação em Educação da Universidade de Uberaba. Professor colaborador do Programa de PósGraduação em Educação da Universidade Federal de Uberlândia. E-mail: jcaraujo.ufu@ gmail.com
} 


\begin{abstract}
The object of this research is a comparative one, and involves two pedagogical manuals, destined to the teacher formation, that came to public in Brazil in the second half of the nineteenth century, one of French origin, and the other Brazilian. The conceptions of Education, theoretical angle of Pedagogy, present in them will be privileged. Its authors are, in order, Jean-Baptiste Daligault and Braulio Jayme Muniz Cordeiro. These manuals will be focused as singular expressions of Essay Pedagogy, through the Christian humanist side, but are based on cultural, political, religious, educational and school relations. On the one hand, they are singular in relation to the social totality, constituting themselves as sharers of the process of teacher training and qualification in Brazil, at that time still through the schools of first letters; on the other, in terms of social totality, are rooted in concepts based on Anthropology, Ethics, Metaphysics of theological character, Politics, Civics, Theology, and Pedagogy, but demarcated by the Christian worldview.
\end{abstract}

Keywords: Pedagogy. Pedagogical Manuals. Teacher training. Normal Schools. Pedagogical Theories.

\title{
Resumen
}

El objeto de esta investigación es una comparación entre dos manuales pedagógicos destinados a la formación docente, los cuales vieron la luz en Brasil en la segunda mitad del siglo XIX, uno de origen francés y otro brasileño. Serán privilegiadas las concepciones sobre Educación y la visión teórica de la Pedagogía presentes en ellos. Sus autores son, por orden, Jean-Baptiste Daligault y Braulio Jayme Muniz Cordeiro. Tales manuales serán enfocados como expresiones singulares de la Pedagogía de la Esencia, a través de la vertiente humanista cristiana, pero encontrándose asentados en las relaciones culturales, políticas, religiosas, educacionales y escolares. De un lado, son singulares con respecto a la totalidad social, constituyéndose como participantes del proceso de formación y calificación docente en Brasil, entonces todavía a la altura de las primeras letras; de otro lado, en términos de totalidad social, están anclados en concepciones fundamentadas en la Antropología, la Ética, la Metafísica de carácter teológico, en la Política, el Civismo, la Teología, la Pedagogía y por eso demarcadas en la visión cristiana del mundo.

Palabras-claves: Pedagogía. Manuales Pedagógicos. Formación de Profesores. Escuelas Normales. Teorías Pedagógicas. 


\section{Delineamentos em torno da História da Educação Comparada}

Em perspectiva historiográfico-educacional, o objeto desse artigo abrange dois manuais pedagógicos: (i) o de M. ${ }^{2}$ Jean-Baptiste Daligault ${ }^{3}$ (1811-1894), nascido em La Chapelle-Biche, atual Normandia, a oeste de Paris, França, cujo manual se intitula Cours practique de Pédagogie destiné aux élèves-maitres des écoles normales primaires et aux instituteurs em exercice, que teve sua $1^{\text {a }}$. edição em 1851; (ii) e o de Braulio Jayme Muniz Cordeiro, intitulado por Compêndio de Pedagogia organizado para uso dos candidatos ao magistério, que foi publicado em 1874 no Rio de Janeiro.

Ambos situam-se entrelaçados, o que lança desafios à história da educação comparada, mas em moldes diversos da orientação comparativa tradicional. Ou seja, embora a comparação etimologicamente implique em um radical que se refere ao par, ao igual, ao parelho, e envolva o semelhante, e díspar se refira ao dessemelhante, ao diferente, ao desigual, não se pode reduzir o comparar como busca e identificação das semelhanças e das diferenças.

Tal redução às semelhanças e às diferenças tem sido objeto de críticas, questionamentos e debates entre aqueles que se envolvem com estudos comparativos. $\mathrm{E}$ uma das razões pode ser atribuída ao lugar da comparação no âmbito do fazer científico, que contém em si três níveis - a descrição, explicação e interpretação - as quais se constituem em fundamentos da construção científica.

Característica da pesquisa histórica é a dimensão documental, sempre aliada à pesquisa bibliográfica, que passa pelos denominados estados da arte, estado da questão ou do conhecimento ou ainda revisão de literatura. Diga-se que as pesquisas bibliográfica e documental sejam os esteios do método, as quais podem implicar em várias técnicas de pesquisa.

No entanto, as operações lógico-metodológicas são diversas, e são convocadas para operar em torno do processo de investigação em vista da descrição, explicação e interpretação. Dentre tais operações, que são de caráter mental, podem ser citadas algumas: abstração, ampliação, análise, associação, categorização, causalidade, classificação, comparação, conceituação, contextualização, correlação, diferenciação, frequência, generalização, indução, quantidade, qualidade, sistematização, semelhança. Ressalte-se ainda que essas operações se constituem em tarefas reconhecidamente universais pelo homem.

\footnotetext{
${ }^{2} M$. na França é uma abreviação de Monsieur, que significa senhor, uma forma de tratamento que geralmente antecede o sobrenome de um homem.

${ }^{3}$ Jean-Baptiste Daligault (1811-1894) chegou a seguir carreira eclesiástica, cursando teologia por um ano; depois foi preceptor, e em 1833 tornou-se bacharel em Letras; entre 1833 e 1837, foi professor no Liceu de Caen, atual Normandia, a noroeste da França. Ao final de 1837, tornou-se sub-inspetor de escolas primárias, depois inspetor, permanecendo nessa função até meados de 1849. Nos meados desse ano, passou a pertencer à Escola Normal de Alençon, atual Normandia, onde se tornou seu diretor até 1871, quando se aposentou. Seu Cours pratique de Pédagogie, primeira dentre outras obras, teve sua $1^{\mathrm{a}}$. edição em 1851, certamente associada aos seus vínculos como diretor e professor da referida Escola Normal de Alençon. Sua $2^{a}$. edição aconteceu em 1853, e a $3^{a}$. em 1864; em 1871, estava em preparação uma $4^{a}$. edição, mas o projeto foi abandonado. Faleceu a 03 de agosto de 1894, com 83 anos (SURVILLE, 1908).
} 
Se assim for, a comparação é uma operação dentre outras, que tem por tarefa os três níveis científicos mencionados. Certamente, para a descrição sua contribuição é menor, porém ela é muito importante para a construção da explicação e da interpretação. Entretanto, a comparação não é solitária no processo de investigação. As operações lógico-metodológicas mencionadas anteriormente também se somam, diferenciadamente, em termos de importância e em termos de convocação a constituírem o processo de investigação.

Nessa direção, e retornando ao objeto dessa investigação, os manuais pedagógicos em apreço podem ser situados e assumidos pelos diferentes processos lógicometodológicos mencionados. Alguns exemplos: seus conteúdos podem ser objeto de categorizações, de associações, conceituações, correlações, generalizações, sistematizações, contextualizações etc.

Conforme José D’Assunção Barros (2014), a História Comparada, nas duas últimas décadas, trouxe à tona várias abordagens: História Cruzada, Histórias Conectadas, World History, Global History e Big History. Para ele, a História Cruzada também está voltada para uma discussão teórico-metodológica sobre o uso da comparação na pesquisa histórica. Além de evocar a pluralidade, a comparação relaciona

[...] formações sociais, culturais e políticas, admitindo desde o início que elas mantêm relações entre si. Esta abordagem convida ao questionamento da historicidade dos objetos e dos procedimentos de análise, assinalando-os como um empreendimento auto-reflexivo gerador de sentidos [...] (ARAUJO; VALDEMARIN; SOUZA, 2015, p. 30).

Por esse foco, o objetivo dessa investigação é comparar os dois manuais referidos, de modo a explicitar suas características, suas singularidades, suas relações e suas distintas fontes. Tal comparação tem por objeto os conteúdos referidos às finalidades da Educação, considerando-se esta como ângulo teórico da Pedagogia, como Ciência da Educação, a qual também compreende uma dimensão prática, denominada por Bráulio Cordeiro (1874), por metodologia. Todavia, a comparação a ser empreendida estará afeta somente às finalidades da Educação, uma vez que explicitam ideias pedagógicas conectadas, ou conforme o linguajar de Barros (2014), ideias pedagógicas cruzadas.

Muitas indagações são possíveis em termos de norteamento geral. Dentre outras: em que termos se estabelecia, à altura dos anos de 1870, a construção da Pedagogia, Ciência da Educação, em contexto europeu? Qual é a relação dos manuais em apreço em vista dessa construção? Quais princípios, diretrizes e prescrições são comuns aos manuais pedagógicos em vista da formação docente? Em relação à disseminação das escolas normais, qual é a situação brasileira nos anos de 1870 em relação à formação docente? Como se coloca a França nessa mesma conjuntura? Como se situam as finalidades física, intelectual, moral, religiosa e cívica nos manuais em pauta? Quais são as demarcações estabelecidas em torno da formação do professor a partir dessas cinco finalidades? 
Enquanto expressões de uma teorização pedagógica, o que as informa do ponto de vista antropológico-filosófico, ético/moral, nacional/cívico, teológico/religioso e físico?

Salvaguarde-se que a comparação goza de centralidade nessa investigação, tornando-se eixo básico e diretor para focalizar os dois manuais-objeto, tendo em vista localizar suas aproximações e distanciamentos. O eixo fundado na perspectiva da comparação, por conseguinte, não tem como alvo "[...] escrutinar as diferenças socioculturais. [...] baseiam-se mais num procedimento implícito de 'observação internacional', [...] com a intenção de 'sintetizar os problemas, ideias e correntes educacionais, comuns a todas as nações"” (SCHRIEWER, 2000, p. 115-116).

Para Barros (2014), [...] a história cruzada relaciona [...] formações sociais, culturais e políticas, partindo da suposição que elas mantêm relações entre si” (p. 117). Nesse sentido, a História Comparada, que abrangeria também a História da Educação, seria compreendida como sinônimo de 'procedimentos relacionais' (BARROS, 2014, p. 117). E a História Cruzada que evoca "A imagem da cruz, efetivamente, permite pensar pontos de intersecção entre as diversas realidades em cruzamento" (Ibidem, p. 117).

Tal norteamento romperia, por conseguinte, com a perspectiva de linearidade, com a sobreposição de algo atuando sobre outro; "[...] insurge-se contra aquelas práticas de história comparada que recaíram em operações estabilizadoras, meras superposições de objetos ou realidades isoladas unidas por um liame de análise [...]" (Ibidem, p. 121). Trata-se, então, de ressaltar as interações, as influências mútuas, os entrelaçamentos etc.

Dessa forma, não se trata de compreender a influência do manual pedagógico francês, o de Daligault (1851) sobre o de Braulio Cordeiro (1874). Trata-se de construir escalas diferenciadas de observação entre Brasil e França em dimensão macroscópica, mas também em dimensão microscópica, no caso, vinculada às finalidades educativas expressas diferenciadamente pelos manuais brasileiro e francês.

[...] não são as atitudes mentais de 'distanciamento' e 'perspectivismo', enquanto características da investigação histórica e dos estudos comparados, que determinam as referências à tradição ou a situações mundiais, respectivamente [...]. Ao invés, ambas as formas de externalização, apesar de fazerem referência a uma abertura sistémica de autoreflexão em relação ao exterior, permanecem 'actos interpretativos internos ao Sistema, que não fornecem informação fidedigna acerca da forma como os processos históricos na realidade ocorreram, ou acerca do que, de facto, está a acontecer no mundo (SCHRIEWER, 2000, p. 117).

O Cours Practique de Pédagogie de Jean-Baptiste Daligault (1851) e o Compêndio de Pedagogia de Braulio J. M. Cordeiro (1874) são concebidos, portanto, como expressões singulares da constituição da formação docente no Brasil, embora sejam de origem diversa, espacial e temporalmente; entretanto, estão entrelaçados, posto que a obra de Bráulio Cordeiro recomenda expressamente a de Daligault dentre outras. 


\section{Teorização Educacional como Referencial Teórico}

De maneira geral, a locução, manual pedagógico, é comumente referida a impressos escolares ou a livros escolares ou ainda a livros didáticos, e tratados como fontes primárias. Quando são compreendidos como tais, constituem-se eles de "[...] um corpo de saberes específicos dos professores" (CATANI; SILVA, 2013). Mas, o que são saberes específicos do professor?

A resposta a essa questão caracteriza melhor o que vem a ser um manual pedagógico: "Os textos escolares disponibilizaram para os estudantes determinados saberes e valores morais, religiosos ou políticos" (CATANI; SILVA, 2013). E eles se destinam a "[...] ensinar a ensinar, explicando a relação pedagógica, as regras da vida escolar, o uso de determinados métodos em sala de aula, o desenvolvimento social, psicológico e fisiológico dos alunos" (CATANI; SILVA, 2013).

Em termos de referencial teórico, que implica um modo de ver o objeto proposto - diverso do modo de fazer que passa pelo método, que abarca um conjunto de processos e operações que se cingem também de técnicas de pesquisa - tem como ponto de partida os conteúdos dos manuais, que se constituem como expressões de uma dada teorização pedagógica, manifesta em torno de concepções vinculadas a uma dada antropologia filosófica, representada por marcos conceituais em torno da educação através dos ângulos físico, moral, intelectual, religioso e cívico, como é o caso do manual de Cordeiro (1874).

Nesse aspecto, revelam-se os manuais possuidores de fundamentação de ordem científica (biologia, psicologia e sociologia, ainda que de modo insuficiente e insatisfatório àquela altura, porque tais ciências se situavam em seu nascedouro) e nãocientíficas como o são as concepções filosóficas (no caso, advindas em particular da Antropologia, da Ética e da Política) e as teológicas de caráter cristão-católico, no caso destas, presentes em ambos os manuais em apreço.

Tal teorização exprime uma característica peculiar, a de sua orientação para a atividade educativa, o que lhe confere um caráter prático, prescritivo, aconselhador, recomendatório, e não apenas explicativo. Nessa ordem, são os manuais em foco expressões singulares da Pedagogia essencialista, caracterizáveis como representantes de uma concepção humanista tradicional, de orientação confessional-católica, que situa a Educação como modelação - similar à atividade do artesão em relação à argila - que atua desde externamente sobre o educando.

\section{Comparando os Manuais Pedagógicos de Daligault (1851) e Cordeiro (1974)}

Em relação à comparação entre os referidos manuais, realizou-se ela pelo cotejamento, pelo entrecruzamento, pelo entrelaçamento, pela analogia, pelos contextos diversificados da origem de ambos, e de sua disseminação no Brasil no decorrer dos anos que cobrem a edição francesa de 1851 por parte de Jean-Baptiste Daligault (seu manual é publicado no Brasil em 1865 e em 1874, respectivamente, primeira e segunda edição) e a edição brasileira por parte de Bráulio Cordeiro em 1874. 
Inicialmente, e a esclarecer tal percurso comparativo: embora não haja, no manual de Daligault, cinco capítulos, correspondentes às dimensões física, intelectual, moral, religiosa e nacional (ou cívica) como explicita o de Cordeiro, a comparação se viabilizou porque elas estão presentes no de Daligault sob outra forma, o que permite assumi-las como categorias estruturantes do processo dessa pesquisa, bem como o referencial em torno da Educação, como dimensão teórica da Pedagogia.

Nesse sentido, a comparação foi o guia das outras operações lógico-metodológicas anunciadas, todavia, todas se constituíram, para mais ou para menos, como diretrizes que metodizaram o processo da pesquisa. Tal comparação também permitiu evocar uma pluralidade de aspectos que passaram pela França (Paris é o local da editora) e Brasil (Recife e Rio de Janeiro, locais da publicação), o que promoveu a explicitação da historicidade de tais edições em relação aos dois países envolvidos, e implicou em procedimentos próprios à comparação, em vista dos laços culturais entre a França e o Brasil historicamente constituídos no decorrer do século XIX em particular.

É nesse sentido que se trata de uma comparação que leva em conta histórias cruzadas, interconectadas ou entrelaçadas, nas quais se fizeram presentes as dimensões macro-histórica e micro-histórica, ambas próprias para compreender os manuais pedagógicos em tela.

Em primeiro lugar, algumas informações sobre Bráulio Cordeiro: nascido a 31 de janeiro de 1829, foi "Professor Público vitalício de segunda classe da instrucção primaria da província do Rio de Janeiro e membro fundador do Instituto Pedagogico de Nictheroy" (CORDEIRO, 1874, p. III). A. A. da Cruz Coutinho Editor é o responsável pela publicação de sua obra.

Em sua dedicatória, datada de 22 de novembro de 1873, ao Senador Barão de Camargos, Braulio Cordeiro circunstancia a sua obra, que resultara de estudos feitos por ele para concorrer a um concurso: "Quando, preparando-me para o concurso da primeira cadeira da Escola Normal, de 22 de julho de 1868 [...], escrevia estas tiras, não pensava que fossem publicadas" [...] (Idem, p. VII).

Uma outra circunstância a pormenorizar: em sua apresentação, intitulada $A o$ Leitor, Braulio Cordeiro reconhece a carência de um compêndio de Pedagogia, justificando-a da seguinte forma: "[...] instado por alguns collegas e pessoas entendidas vai este [Compêndio] correr mundo, despido porém de quaesquer pretenções" (Ibidem).

É significativo ainda um trecho de sua apresentação, Ao Leitor, pela qual Braulio Cordeiro assume que sua obra é um plágio e uma compilação, porém destaca que suas ideias a respeito de Pedagogia também estão presentes, porque elas são filhas de sua prática, bem como resultam de anotações antigas e de observações pessoais:

Embora este meu trabalho seja um plagio e compilação, devo fazer notar que nem sempre é uma tradução ou resumo do que li, porque contém muitas idéas filhas de minha pratica e experiência, notas antigas que methodisei, observações importantes que marginavão meu canhenho de lembranças, que se baralharão com as dos outros que compilei (CORDEIRO, 1874, p. VI). 
Em relação ao título da obra de Braulio Cordeiro, os destinatários também o compõe. Em sua época, é comum encontrar-se títulos ou subtítulos como 'destinado às escolas normais' ou ainda 'rigorosamente de acordo com o Programa Oficial das Escolas Normais' ou 'organisado para uso dos candidatos ao magistério', como é o caso do Compêndio de 1874. Em vista disso, caracteriza-se este, de um modo geral, por apresentar um molde didático, uma vez que tem em vista a formação do professor.

Contextualizando a obra de Braulio Cordeiro: a essa altura, 1874 no Brasil, data de publicação do Compêndio em análise, conta-se com uma dezena de escolas normais a cuidar da formação do professor. Segundo Antonio de Almeida Oliveira (2011), um maranhense, em obra publicada em 1874, a ideia de criação de escola normal "[...] nasceu entre nós em Minas no ano de 1835, [...] em 1847 já contava o Império com quatro escolas normais" (OLIVEIRA, 2003, p. 213). Depois acrescenta:

[...] hoje [1874] apenas 10 existem, e entre essas não se contam duas do período de 1847. [...] A falta de escolas normais em 10 províncias pode atribuir-se numas à exiguidade dos seus recursos, noutras à incúria dos seus legisladores: em nenhuma a defeito da ideia, pois nunca a experimentaram (OLIVEIRA, 2003, p. 213).

Pode-se perscrutar, por isso, que o universo civilizatório, de ordem educacional no Brasil, em que se colocava a profissão docente, estava por ser construído. E desta construção, a obra de Bráulio Cordeiro é participante, uma vez que o seu Compêndio se destinava aos candidatos a concurso ao magistério.

Em relação ao contexto europeu, as escolas normais também se efetivaram, bem como se disseminaram paulatinamente a partir da primeira década do século XIX, pela futura República italiana, pela Prússia através de Wilhelm Humboldt (17671835). Na França, embora tenha havido a aprovação de um projeto de Joseph Lakanal em 1794, ele não se efetivou. Posteriormente, foi com Napoleão, em 17 de março de 1808, que se criou a universidade francesa, denominada por modelo napoleônico ou francês. Por esse decreto, o artigo 107 expressava a seguinte diretriz em relação ao que envolvia a escola normal:

Serão tomadas pela Universidade todas as medidas para que a arte de ensinar a ler, a escrever e as primeiras noções de cálculo nas escolas primárias, não seja exercida de hoje em diante senão por mestres muito esclarecidos para comunicar fácil e seguramente estes primeiros conhecimentos a todos os homens (BUISSON, 1911, p. 1998).

Outras tentativas passaram pelo decreto de 25/04/1815, que também apontava na mesma direção, ou seja, a escola normal como modelo ou como padrão. O número de escolas normais na França em 1833 chegou a 48 (Ibidem, p. 1418). 
No caso brasileiro, antes de 1880, a grande maioria dos professores não se beneficia, portanto, de uma formação específica que seria dada em uma escola ou um curso normal, e isso em razão de seu frágil número. Em 1877, há somente cerca de 200 normalistas que se formam por ano. Em, 1887, as normalistas são perto de 1.000 mas elas constituem sempre menos de $2 \%$ dos titulares leigos (TREVISAN; PEREIRA, 2013, p. 223).

Em suma, é no decorrer do século XIX que se concebeu a formação profissional dos professores como algo capital e indispensável. Saber e saber ensinar eram aspectos distintos, e ao professor cabia cuidar das duas dimensões. Conclusivamente, segundo Cambi (1999, p. 492),

[...] no curso do século XIX, - da Época Napoleônica até a crise do fim do século -, desenvolve-se um processo bastante articulado no que diz respeito à instituição-escola, embora dividido em etapas não-homogêneas e manifestado de forma diferente nos vários países europeus e americanos.

Por conseguinte, é no interior do processo de disseminação das escolas normais que a formação do professor irá ser institucionalizada, mesmo que através dos cursos complementares e das conferências práticas. É sob a direção de tais iniciativas com a crescente criação de escolas normais, bem como pela demanda das atividades de formação promovidas no interior das universidades, que devem ser compreendidas, se não as origens dos manuais pedagógicos, pelo menos sua paulatina disseminação e sua variedade, o que implicou no número crescente deles.

No caso brasileiro, esse movimento não se desenvolveu, mas a tradução de um primeiro manual francês no Brasil se deu em 1865 em Recife, PE, ou seja era a primeira edição do manual de Jean-Baptiste Daligault referido anteriormente. Isso implica em reconhecer que o Brasil se fazia então sintonizado com a formação do professor na França, ainda que em nível precário, uma vez que a criação e manutenção de escolas normais públicas foram muito instáveis com relação ao funcionamento, como salientou A.A. Oliveira (2011), referido anteriormente (Cf. também ARAUJO; FREITAS; LOPES, 2008).

Nesse sentido, e agora com foco no manual de Braulio Cordeiro (1874), uma análise estrutural do mesmo se revela, já na Introdução (p. IX-X), que a Pedagogia é definida como "[...] sciencia que trata dos princípios methodicos, leis fundamentaes do ensino, educação e meios práticos de conduzir a infância ao seu fim pelo caminho da moral e do saber" (Idem, p. IX). Para Daligault (1851), “A Pedagogia é a arte de bem elevar as crianças ou de dar-lhe uma boa educação: arte importante, que exige razão, luzes, experiência e dedicação" (p. 45).

Em relação à sua Primeira Parte, Cordeiro (1874) divide-a em cinco tópicos: Educação Física, Educação Moral, Educação Intelectual, Educação Religiosa e Educação Nacional. Tais conteúdos ocupam as páginas 5 a 36. Diferentemente, a obra de Daligault (1851) define somente três ramos de educação: física, intelectual e moral "[...] com a qual se confunde a educação religiosa" (p. 45). 
Em Cordeiro (1874), a referência aos preceitos da moral e da religião implica em compreender uma tradição mais que milenar, a da primazia da religião católica no âmbito da cultura ocidental. Ressalte-se também que a dimensão moral é informada pela concepção religiosa, o que leva a compreender, inclusive, que não se pode sustentar uma moral sem religião. Esta seria o fundamento daquela. Trata-se, portanto, de uma moldagem derivada da tradição católica estabelecida no Brasil, desde 1500, com a celebração da primeira missa em terras brasileiras.

Como a ética cristã compõe o universo da cultura ocidental, a educação, a instrução, a escola e o professor deveriam cuidar dessa associação. A obra de Braulio Cordeiro (1874), portanto, está inserida em um contexto oficialmente católico. Sua pertença à concepção tradicional religiosa católica é evidente em muitos aspectos, como já foi observado, através da inclusão da educação religiosa como um dos fundamentos da atividade educativa; na verdade, a perspectiva religiosa se apresenta como carro-chefe, porque coordena todas as outras educações.

Dentre as cinco educações mencionadas, cabe iniciar-se pela (i) educação física (CORDEIRO, 1874, p. 5-10). Nestas, expõe a respeito dos diferentes modos de encarála, os quais envolveriam as deformidades do corpo, a prevenção, a higiene, a ginástica, o papel dos pais, em especial o da mãe, o papel dos asilos. Afirma que alguns autores tratam da educação física, referindo-a à família e à escola.

Com relação ao manual de Daligault, posiciona-se Cordeiro (1874) de que ele “[...] segue outro rumo, deixa a casa paterna entregue aos desvellos de seu chefe, e, entrando na sala do estudo, dá regras ao mestre sobre a hygiene escolar" (p. 6). No entanto, é baseado no manual de Daligault (1851) que destaca o papel do mestre em relação à salubridade da escola.

Daligault (1851) também discorre a respeito do papel dos pais, porém enfatiza o papel do professor primário, distinguindo, de um lado, 'meios indiretos ou precauções higiênicas', tais como: asseio das crianças, limpeza do local, ventilação, necessidade de exercícios variados, porte das crianças, separação das crianças atingidas por certas enfermidades; de outro, refere-se aos 'meios diretos ou exercícios', estendendo-se sobre a marcha, corrida, salto, escalada, esquiação (1851, p. 46-54).

Bráulio Cordeiro (1874) define que "a educação physica tem por fim o emprego dos meios conducentes a conservar a saúde dos meninos e prevenir os efeitos de causas conhecidas" (p. 6). Levando-se em conta a salubridade da escola, o mesmo Braulio Cordeiro (1851) estabelece sete preceitos que cabem atenção por parte do mestre: ar, vestuário, contágios, trabalho, asseio, jogos e exercícios (Idem, p. 7-10).

Com relação à (ii) educação moral, tratada entre as p. 10 e 20, Cordeiro (1874) explicita dois aspectos a se ter em conta: qualidades a criar e defeitos a combater, cabendo à educação moral o de contrair bons hábitos, salientando-se a seguir a explicitação da dimensão ética fundada no cristianismo.

O sentimento moral eleva o homem acima de todas as outras criaturas: o mestre deve, portanto, afastar o menino do mal e o conduzir ao bem; destruir todos os germens impuros, as inclinações perversas, os instinctos brutaes que apparecerem, e incutir em sua alma a crença, as paixões nobres, as virtudes christãs e sociaes que exaltão o homem até fazel-o justo. (p. 10) 
Estabelece posteriormente sete qualidades a promover: franqueza, ordem, pudor, atividade, civilidade, obediência e exatidão. E os defeitos a combater também somam sete: distração, orgulho, sensualidade, preguiça, ambição, perversidade e egoísmo. Em Daligault (1851), as educações moral e religiosa são tratadas entre as p. 184 e 213. Em termos de arcabouço conceitual,

Mais importante do que a educação intelectual, que esclarece o espírito, a educação moral forma coração, isto é, ela corrige os defeitos do caráter, ela elimina ou prevê os maus hábitos, ela dispõe a vontade a seguir os preceitos da virtude, em uma palavra, ela assegura a observação da lei que todo homem, vivente em sociedade, encontra gravada no fundo de seu coração, e que se chama lei natural. (p. 184)

Para ele, esta lei emana de Deus; do contrário, ela seria uma inexplicável ilusão do espírito humano. Com essa interpretação, considera a lei natural como lei religiosa. "De um outro modo, a lei religiosa propriamente dita reproduz exatamente os preceitos da lei natural" (Ibidem, p. 184).

É por essa forma de pensar que Daligault (1851) considera “[...] impossível isolar a religião da moral e esta da religião" (p. 184). É nesse diapasão que situa sua explicação a respeito do tratamento dado à Terceira Parte, intitulada por Educação Moral e Religiosa. Inclusive, ampara-se em Voltaire, ao citar sua posição de que a religião natural "é o começo do cristianismo, e o cristianismo é a lei natural aperfeiçoada" (p. 184, em nota de rodapé).

Conclui tal arcabouço conceitual, atentando que é pela dimensão moral e religiosa que o professor primário se torna verdadeiramente útil aos alunos. Para o seu êxito, o referido professor necessita estudar o caráter das crianças, combater certas falhas muito comuns em sua idade, fazê-las adquirir certas virtudes essenciais, bem como empregar meios eficazes para fortalecer o instinto moral e o sentimento religioso.

Em relação à (iii) educação intelectual, desenvolvida entre as p. 21 e 28, sua finalidade, segundo ele, é o cultivo do espírito por meio das operações do pensamento. "A atividade da alma é a causa de nossas ideas; ella forma a inteligência, a faz nascer, a desenvolve e lhe dá toda a sua perfeição" (CORDEIRO, 1874, p. 21).

A seu ver, tais faculdades são três: atenção, comparação e raciocínio; e o papel do mestre deve centrar-se em desenvolvê-las e aperfeiçoá-las. Em seguida, fixa que são sete as qualidades que precisam ser cultivadas: atenção, coração, razão, imaginação, memoria, entendimento e apreensão (Ibidem, p. 22-28).

Por sua vez, Daligault (1851) estabelece que "A educação intelectual tem por objeto desenvolver a inteligência, isto é, torná-la mais capaz de aprender e de conhecer" (p. 55). Para isso, trata-se de colocar em ação as diversas faculdades intelectuais, tais como a percepção, a atenção, a memória, a imaginação, o julgamento, o raciocínio.

E o papel do professor primário é o de aproveitar-se de todas as ocasiões para colocar em ação tais faculdades. Reconhece que a educação intelectual se confunde com a instrução, uma vez que ambas buscam um fim comum. Ainda que sejam distintas, “[...] a educação intelectual abre o caminho para a instrução, e esta completa a obra da primeira" (Ibidem, p. 56). 
Diferentemente de Bráulio Cordeiro (1874), Daligault (1851) considera que o processo da educação intelectual necessita de várias condições: que o professor primário tenha à sua disposição um local agradável, mobiliário conveniente, manutenção da ordem e da disciplina e um bom método de ensino. Com tais temas, a obra de Daligault (1851) se ocupa entre as p. 57 e 183, detalhando-os expressivamente.

Com relação à (iv) educação religiosa (desenvolvida entre as p. 29 e 31), Cordeiro (1874) considera que seu fim "[...] é plantar uma crença no coração do menino e indicarlhe qual a sua missão na terra como christão" (p. 29). E que cabe "[...] incutir em seu coração [menino] a crença, sem a qual a humanidade faltará a seu fim, tanto na terra como no céo" (Idem, p. 29). "Os princípios de moral ensinados á infância devem ser taes que a sua inteligência os compreenda e se gravem na memoria e no coração de modo que nunca mais possão ser esquecidos" (Ibidem, p. 30).

Estabelece, novamente em relação a essa dimensão religiosa da educação, sete preceitos: promover no menino a verdadeira crença e um culto sincero; tornar o menino adorado de Deus e feliz na vida e na outra através do conhecimento do mesmo; cultivar o estudo das coisas divinas e a beleza do Cristianismo; preparar o menino para a aquisição de virtudes através da leitura; imprimir em sua memória as principais verdades da doutrina cristã e os eventos mais significativos da História Sagrada; obrigar o menino a ocupar-se destas verdades, bem como à prática de atos piedosos; e, finalmente, cabe ao professor sufocar os maus pensamentos do menino, elevando sua alma a Deus e ensinando-lhe os deveres do homem em relação à família e à pátria (Ibidem, p. 31).

Finalmente, somente a (v) educação nacional é desenvolvida por Cordeiro (1874) entre as p. 32 e 36, a qual também poderia ser denominada por educação cívica. Sua finalidade é "[...] fazer do menino um homem amante de sua pátria, pela qual deve sacrificar vida e bens" (Ibidem, p. 32). Entre as páginas 33 e 36 desenvolve o conteúdo relativo também a sete preceitos, os quais cabem ao mestre incutir e explicar aos meninos. São eles:

$1^{\circ}$. Adesão à forma de governo, pela qual se refere ao fato de que o Brasil é governado por quatro poderes políticos, dos quais o Imperador é a chave. Tais poderes se referem ao Legislativo, ao Moderador, ao Executivo e ao Judicial.

$2^{\circ}$. Argumenta a favor do sustentáculo das instituições juradas, o que implicava tornar o menino conhecedor dos princípios 'de nosso evangelho político', da excelência de sua doutrina fundada na liberdade de consciência, de pensamento, de opinião, de commercio, de indústria, de tribuna e de imprensa.

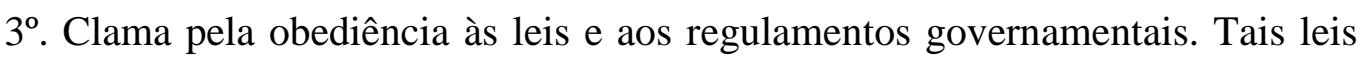
são concebidas pelo autor como necessárias para a boa administração da ordem, civil, criminal, orfanológica, militar, financeira etc. Justifica que tais leis "[...] feitas por cidadãos escolhidos livremente pelo povo, e que, expirando o seu mandato são tanto como os outros e sujeitos também a ellas" (Ibidem, p. 34).

$4^{\circ}$. O respeito aos magistrados e às suas decisões argumenta que os mesmos são revestidos de poder conferido pela nação através de suas leis constitucionais. Carecem eles de respeito e acatamento, os quais fundam o princípio da autoridade e a ordem em ação.

$5^{\circ}$. Solicita execução das ordens baseadas na lei, o que envolve o bom exemplo: 
[...] para que o povo não soletre o cumprimento de deveres como indício de absolutismo ou infracções adrede feitas para nosso mal; explicando-lhe também que é dever do cidadão rodear a justiça do prestígio conveniente para não ser desacatada pelos perturbadores da ordem publica (Ibidem, p. 34-35).

$6^{\circ}$. Sustenta-se na defesa da prontidão em pegar em armas, o que tem em vista

[...] o imperioso dever de sustentar a sua integridade e independência; de derramar seu sangue pela desaffronta da honra nacional ultrajada; de achar-se sempre ao lado do governo legal, empunhando a bandeira imperial, symbolo sagrado de nossa união e grandeza. (Ibidem, p. 35)

$7^{\circ}$. Defendia a exação no pagamento dos impostos, porque se trata de uma obrigação estabelecida por lei que se destina ao

[...] esplendor da majestade, boa representação de nosso paiz, o custeio de um exército respeitável e de uma marinha imponente, apoio comum a todos os cidadãos, instrucção publica, abertura de estradas, navegação de rios, animação a todas as fontes da riqueza publica; agricultura, indústria, artes, officios, etc., emfim, justiça e garantia individual. (Ibidem, p. 35-36)

As concepções de educação expressas por essas cinco dimensões permitem afirmar que a educação religiosa é o fundamento arquitetural da educação. O Compêndio de Pedagogia de Braulio J. M. Cordeiro (1874) é uma expressão brasileira a participar da modalidade conhecida por manual pedagógico, o que na Europa esteve presente desde o final do século XVIII (CHOPIN, 2008).

\section{Considerações Finais}

A compreensão que os manuais de Braulio Cordeiro (1874) e de Daligault (1851) deixa manifesta é o vínculo da Pedagogia, Ciência da Educação, com a religião católica, seu fundamento. Nesse sentido, a teleologia católica mobiliza uma concepção antropológica, ética e política, que é inerente à concepção de educação.

Com exceção da educação física, todas as outras quatro apresentam referências explícitas às virtudes cristãs (educação moral); ao papel da religião como contrapeso à imaginação (educação intelectual); ao papel do cristão na terra, à recomendação de se conhecer a história sagrada, em tornar o menino um adorador de Deus ou a elevar sua alma a Deus (educação religiosa); os sete preceitos relativos à educação nacional, 
mencionados há pouco, acabam por legitimar o poder político do Império brasileiro, uma vez que a religião católica gozava de oficialidade constitucionalizada.

Advoga-se que ambos os manuais estejam assentados em relações culturais, políticas, religiosas, educacionais e escolares, norteadas pela religião católica. São singulares em relação à totalidade social, ou seja: de um lado, constituem-se como frações da formação docente no Brasil, que tinha em vista a ampliação da escolarização primária, bem como a sua qualificação, àquela altura ainda através das propaladas escolas isoladas; de outro, em termos de totalidade social, estão radicados em concepções fundadas na Antropologia, na Ética, na Metafísica de caráter teológico, na Política, no Civismo, na Teologia, na Pedagogia, porém demarcadas pela visão de mundo cristã.

Tal norteamento religioso católico traduz-se, no século XIX, por uma orientação elaborada pelo Concílio de Trento (1545-1563), que concebeu a Igreja como Sociedade Perfeita, sob a qual todas as demais sociedades se situavam, inclusive o Estado; acresçase também o ultramontanismo vigente no decorrer do século XIX, do qual o Brasil participou mais distanciadamente, dado o reconhecimento constitucional da Igreja Católica como religião oficial. Nesse sentido, tais manuais pedagógicos compartilharam das relações políticas, morais, culturais, escolares etc, mas arraigadas na dimensão religiosa e guiadas por ela.

Tal formação mobilizou concepções de variada ordem - tais como a antropológico-filosófica, ética, política, religiosa e cívica, que se produziram pelas relações entre sociedade, Estado e escola no interior da cultura ocidental.

Os compêndios de Cordeiro (1874) e de Daligault (1851) revelaram-se, pelas suas finalidades, legitimadores das relações oficiais entre Igreja e Estado no Brasil, estabelecidas desde a Constituição imperial brasileira de 25/03/1824 até a separação entre Igreja e Estado brasileiro em 07/01/1890, quando tais relações foram interrompidas, formalmente, através de um decreto logo após a Proclamação da República em 15/11/1889.

Entretanto, a concepção de Igreja como Sociedade Perfeita também se fez presente no decorrer do século XX, através de vários manuais pedagógicos, até a autoafirmação da concepção eclesial fundada em Povo de Deus, quando da realização do Concílio Vaticano II (1962-1965), concepção esta resultante de uma elaboração teológica ali constituída.

Para além da singularidade de que goza o referido Compêndio de Pedagogia de Cordeiro (1874), é possível e mesmo necessário realizar uma ampliação que focalize a dimensão que os manuais pedagógicos tomaram, seja nacionalmente ou mesmo em seu entrecruzamento desde o âmbito europeu no decorrer do século XIX, como elucida o manual de Daligault (1851). Nessa direção, os manuais pedagógicos compartilham de um universo cultural, político, religioso, escolar dentre outros aspectos, fundamentais para compreendê-los para além de sua materialidade e dos métodos que põem em circulação. 


\section{Referências}

ARAUJO, J.C.S.; VALDEMARIN, V.; SOUZA, R.F. de. A Contribuição da Pesquisa em Perspectiva Comparada para a Escrita da História da Escola Primária no Brasil: Notas de um Balanço Crítico. In SOUZA, R.F. de; PINHEIRO, A.C.F; LOPES, A.P.C. (orgs.) (2015). História da Escola Primária no Brasil: Investigação em Perspectiva Comparada em Âmbito Nacional. Aracaju, SE: EDISE, p. 27-45.

ARAUJO, J.C.S.; FREITAS, A.M.B.de; LOPES, A.P.C. (orgs.). As Escolas Normais no Brasil: do Império à República. 2a . edição. Campinas, SP: Alínea Editora, 2017.

BARROS, J. D’A. História comparada. Petrópolis, RJ: Vozes, 2014.

BUISSON, F. (dir.). Nouveau Dictionnaire de Pédagogie. Paris: Librairie Hachette et Cie., 1911.

CAMBI, F. História da Pedagogia. São Paulo, Editora da UNESP, 1999.

CATANI, D. B.; SILVA, V. B. Manuais pedagógicos. In: OLIVEIRA, D.A.; DUARTE, A.M.C.; VIEIRA, L.M.F. Dicionário: trabalho, condição e profissão docente. Belo Horizonte: UFMG/Faculdade de Educação, 2010, CDROM (http://www.gestrado.org/?pg=dicionarioverbetes\&id=109. Acesso em 17/04/2015).

CHOPIN, A. Le manuel scolaire: une fausse évidence historique. Revue Histoire de l'Éducation. SHE/INRP, n.117, jan-mars, p.7-56, 2008.

CORDEIRO, B.J.M. Compêndio de Pedagogia organizado para uso dos candidatos ao magistério. Rio de Janeiro: A. A. Cruz Castanho Editor, 1874.

DALIGAULT, M. Cours pratique de pédagogie destiné aux élèves-maîtres des écoles normales primaires et aux instituteurs en exercice. Paris: Dezobry et E. Magdeleine, Libr.Éditeurs, 1851.

OLIVEIRA, A. de A. O ensino público. Brasília, DF: Senado Federal, 2003.

SCHRIEWER, J. Estados-Modelo e Sociedades de Referência: Externalização em Processos de Modernização. In NÓVOA, A.; SCHRIEWER, J. (eds.). A Difusão Mundial da Escola. Lisboa: Educa, 2000.

SURVILLE, A. Notice sur la Vie et les Oeuvres de M. Jean-Baptiste Daligault. Bulletin de la Société Historique et Archeologique de L'Orne. Tome XXVII. Alençon, France, 2008, p. 282-330. Disponível em http://gallica.bnf.fr/ark:/12148/bpt6k54572629/ texteBrut. Acesso em 05/04/2017.

TREVISAN, T.A.; PEREIRA, B.C. Leituras recomendadas para as Escolas Normais no Brasil e na França (século XIX): transferências culturais e de modelos pedagógicos. Patrimônio e Memória, São Paulo, Unesp, v. 9, n. 1, p. 223-237, jan.-jun., 2013. 